\title{
Hubungan Konstruksi Sumur Dan Jarak Sumber Pencemaran Terhadap Total Coliform Air Sumur Gali Di Dusun 3A Desa Karang Anyar Kecamatan Jati Agung Kabupaten Lampung Selatan
}

\author{
Siti Aminah ${ }^{1}$, Septiya Wahyuni ${ }^{2}$ \\ ${ }^{1}$ Prodi Diploma III Analis Kesehatan Poltekkes Tanjungkarang \\ ${ }^{2}$ Alumni Prodi Diploma IV Analis Kesehatan Poltekkes Tanjungkarang
}

\begin{abstract}
Abstrak
Dusun 3A Desa Karang Anyar Kecamatan Jati Agung Kabupaten Lampung Selatan mayoritas masyarakatnya paling banyak memiliki sumur gali sebagai sumber air bersih dan memiliki hewan ternak.Letak sumur gali banyak yang berdekatan dengan kandang ternak dan septic tank yang jaraknya < 11 meter dan kondisi konstruksi sumur gali yang tidak memenuhi syarat konstruksi. Penelitian ini bertujuan untuk mengetahui hubungan kontruksi sumur dan jarak sumber pencemaran terhadap total coliform air sumur gali.Pengujian air bersih untuk menentukan total coliform menggunakan metode MPN (Most Probable Number). Analisis data yang digunakan pada penelitian ini adalah analisa univariat. Penelitian pada 60 sampel sumur gali didapatkan hasil konstruksi sumur gali yang tidak memenuhi syarat konstruksi sebanyak $100 \%$ (60 sumur), jarak sumur gali dengan sumber pencemaran yang tidak memenuhi syarat SNI-03-2916-1992 sebanyak $100 \%$ (60 sumur) dan total coliform yang tidak memenuhi syarat Permenkes RI No.416/Menkes/Per/IX/1990 yaitu $\leq 50 / 100$ ml sampel sebanyak $100 \%$ (60 sumur). Berdasarkan penelitian diperoleh hasil 100\% tidak memenuhi syarat disimpulkan ada hubungan antara konstruksi sumur terhadap total coliform dan ada hubungan antara jarak sumber pencemaran terhadap total coliform
\end{abstract}

Kata Kunci: Konstruksi, Jarak, Total coliform

\section{Relationship Construction Well And Distance Source Pollution Against Total Coliform Water Well Dug In Dusun 3A Karang Anyar, Jati Agung, South Lampung}

\begin{abstract}
Dusun 3A Karang Anyar Village Jati Agung Subdistrict, South Lampung District, the majority of the people have the most dug wells as a source of clean water and have livestock. The location of many wells dug adjacent to the cattle pens and septic tanks that are $<11$ meters and the condition of dug well construction that does not meetthe construction requirements. This study aims to determine the relationship of well construction and the distance of pollution sources to the total coliform of well water. Water testing to determine the total coliform using MPN (Most Probable Number) method. Data analysis used in this research is univariate analysis. The research on 60 samples of dug wells was obtained from the construction of dug wells that did not meet the construction requirements of $100 \%$ (60 wells), the distance of dug wells with pollution sources that did not meet the requirements of SNI-03-2916-1992 as much as 100\% (60 wells) and total coliform that does not meet the requirements of Permenkes RI No.416 / Menkes / Per / IX / 1990 is $\leq 50 / 100 \mathrm{ml}$ of sample as much as $100 \%$ (60 wells). Based on the research, $100 \%$ unqualified results concluded that there is a relationship between the construction of wells to the total coliform and there is a correlation between the distance of the source of pollution to the total coliform.
\end{abstract}

Keywords: Construction, Distance, Total coliform

Korespondensi: Siti Aminah, Jurusan Analis Kesehatan. Politeknik Kesehatan Tanjungkarang, Jln. SoekarnoHatta No. 1 Bandar Lampung, mobile 085269394663, e-mail : aminahkurun.ak@gmail.com 


\section{Pendahuluan}

Kabupaten Lampung Selatan adalah salah satu kabupaten di Provinsi Lampung. Ibu kota kabupaten Lampung Selatan terletak di Kalianda. Berdasarkan profil Kabupaten Lampung Selatan, wilayah Kabupaten Lampung Selatan tersebar di 246 desa, 4 kelurahan dan 17 kecamatan (Dinkes, 2014).

Hasil survei yang telah dilakukan, dusun 3A desa Karang Anyar terdiri dari 2 RT dengan jumlah kepala keluarga adalah 246.Penduduk dusun 3A desa Karang Anyar mayoritas untuk memenuhi kebutuhan air bersih sehari-hari menggunakan air sumur gali.Masyarakat Dusun 3A paling banyak memiliki sumur gali yang letaknya berdekatan dengan kandang ternak dan septic tank yang jaraknya < 11 meter dan konstruksi sumur yang tidak memenuhi syarat. Berdasarkan profil kesehatan Kabupaten Lampung Selatan tahun 2012 penyakit diare masuk kedalam sepuluh besar penyakit Kabupaten Lampung Selatan, profil kesehatan Kabupaten Lampung Selatan tahun 2014 jumlah perkiraan kasus diare di Karang Anyar sebesar 1.706 dan berdasarkan laporan rekapitulasi penderita diare di UPT Puskesmas Karang Anyar tahun 2016 wilayah kerja yang mencakup dusun 3A berjumlah 1.679.

Untuk mengetahui jumlah colifom di dalam sampel biasanya digunakan metode MPN (Most Probable Number) (Irianto, 2013).

Penelitian sejenis Dewi K (2016) tentang Gambaran MPN Coliform Fekal Pada Air Sumur Gali Desa Tanjungsari VI Kecamatan Natar Kabupaten Lampung Selatan, dari 35 sampel yang diperiksa didapatkan hasil 27 sampel tidak memenuhi syarat jumlah MPN coliform yaitu >50/100 ml berdasarkan Permenkes No.416/Menkes/Per/IX/1990, dan penelitian yang dilakukan oleh Ramadhani $\mathrm{N}$ (2016) tentang Gambaran MPN Coliform Fekal Pada Air Sumur Gali Di RW 12 Kelurahan Hadimulyo Timur Kecamatan Metro Pusat Kota Metro , dari 40 sampel yang diperiksa didapatkan 28 sampel tidak memenuhi syarat jumlah MPN coliform yaitu > 50/100 ml berdasarkan

No.416/Menkes/Per/IX/1990.

Menurut Peraturan Pemerintah RI No. 82 tahun 2001 Pencemaran air adalah masuknya atau dimasukkannya makhluk hidup, zat, energi dan komponen lain ke dalam air atau perubahan tatanan air oleh kegiatan manusia.

Indikator tercemarnya sumber air atau badan-badan air ditunjukkan dengan adanya perubahan kualitas air disebabkan oleh peningkatan jumlah beberapa parameter unsur tertentu dari standar yang ditetapkan. Indikator pencemaran bakteri ditunjukkan dengan adanya bakteri coliform.

Pola pencemaran air tanah oleh bakteri

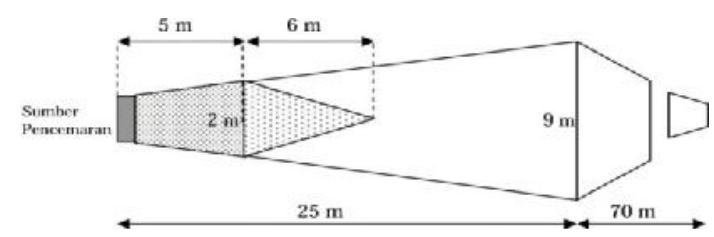

Gambar 1.Pola Penyebaran Mikroorganisme dan Bahan Kimia dalam Pencemaran Terhadap Air Tanah di Sekitarnya. Sumber: Marsono, 2009

Pencemaran yang ditimbulkan oleh bakteri terhadap air yang ada didalam tanah melebar sampai \pm 2 meter pada jarak 5 meter dari sumber pencemaran serta menyempit hingga jarak 11 meter searah dengan aliran tanah. (Marsono,2009).

Persyaratan air bersih yang berlaku di Indonesia adalah yang ditetapkan oleh Menteri Kesehatan yaitu Permenkes RI No.416/Menkes/Per/IX/1990 tentang syarat-syarat dengan pengawasan kualitas mikrobiologi air adalah sebagai berikut:

Jumlah total coliform kadar maksimum yang diperbolehkan maksimum $50 \mathrm{MPN} / 100 \mathrm{ml}$ untuk bukan air perpipaan.Jumlah total coliform kadar maksimum yang diperbolehkan $10 \mathrm{MPN} / 100 \mathrm{ml}$ untuk air perpipaan.

Coliform merupakan suatu grub bakteri yang digunakan sebagai indikator adanya polusi kotoran dan kondisi sanitasi yang tidak baik terhadap air, makanan, susu, dan produkproduk susu. Bakteri coliform dapat dibedakan atas dua grup yaitu coliform fekal dan coliform non-fekal (Irianto, 2013).

Escherichiamerupakan bakteri yang berbentuk batang lurus dengan ukuran 1-4 $\mu \mathrm{m}$, motil atau nonmotil.Bakteri ini ditemukan dalam isi intestinal manusia, hewan berdarah hangat, dan unggas. Escherichiadigunakan sebagai salah satu indicator sanitasi dalam kelompok coliform dan coliform fecal (Sopandi dan Wardah, 2014 ) karena jumlah organisme koliform cukup banyak dalam usus manusia. Sekitar 200-400 miliar organism ini dikeluarkan melalui tinja setiap harinya.Organisme ini lebih mudah dideteksi dibanding tipe kuman patogen lainnya.

Organisme ini lebih tahan hidup dibandingkan dengan kuman usus patogen lainnya.Organisme ini lebih resisten terhadap proses purifikasi air secara alamiah. 
Metode MPN biasa digunakan untuk uji kualitas air ataupun bahan pangan olahan serta produk olahan. Most Probable Number (MPN) adalah metode untuk memperkirakan jumlah kepadatan mikroba pada sampel secara tidak langsung.Metode MPN menggunakan medium cair yang ditempatkan di dalam tabung reaksi.Media yang digunakan untuk metode MPN adalah Lactose Broth (LB) dan Brilliant Green Lactose Bile Broth (BGLBB).Metode MPN lebih sensitif dan dapat mendeteksi coliform dalam jumlah yang sangat rendah didalam sampel (Supardi, 1999).

Uji MPN terdiri dari tiga tahap, yaitu uji pendugaan (presumtive test), uji penegasan (confirmed test), uji kelengkapan (completed test).Uji penduga digunakan Lactose Broth dan uji penguat menggunakan Brilliant Green Lactose Bile Broth (BGLBB). Tabung dinyatakan positif jika terbentuk gas sebanyak $10 \%$ atau lebih dari volume di dalam tabung durham (Irianto, 2013)

Ragam yang digunakan pada MPN ada 3, yaitu : Ragam 511 yang digunakan untuk air yang sudah diolah atau angka kumannya diperkirakan rendah. Ragam 555 yang digunakan untuk air yang belum diolah atau kumannya diperkirakan tinggi. Ragam 333 yaitu ragam alternatif untuk ragam 555 , apabila jumlah tabung terbatas (Soemarno, 2000)

\section{Metode}

Jenis penelitian ini merupakan penelitian survei analitik. Rancangan penelitian yang digunakan dalam penelitian ini menggunakan cross sectional.Variabel penelitian ini meliputi variabel independent konstruksi sumur dan jarak sumber pencemaran, variabel dependent total coliform air sumur gali.

Lokasi Penelitian Dusun 3A Desa Karang Anyar Kecamatan Jati Agung Kabupaten Lampung Selatan dan diperiksa di Laboratorium Bakteriologi Jurusan Analis Kesehatan Poltekkes Tanjungkarang.Penelitian akan dilaksanakan pada bulan April-Mei 2017.

Populasi air sumur gali di Dusun 3A Kecamatan Jati Agung Kabupaten Lampung Selatan berjumlah 150 sumur gali. Dusun 3A terbagi menjadi 2 RT yaitu 001 dan 002.Jumlah sumur gali di RT 001 berjumlah 65 sumur gali dan di RT 002 berjumlah 85 sumur gali.

Sampel pada penelitian ini befjegaltí (60) sampel. Dengan kriteria sampel:-Mempunyai sumur gali dan ada sumber pencemaran septic tank dan kandang ternak.

Pemeriksaan sampel menggunakan metode MPN (Most Probable Number) ragam 3 3

Alat yang digunakan adalah tabung reaksi, rak tabung reaksi, jarum ose, erlenmeyer, inkubator, autoclave, hot plate, timbangan, batang pengaduk, pipet ukur $(0,1$ $\mathrm{ml} ; 1,0 \mathrm{ml} ; 10 \mathrm{ml}$ ), aluminium foil, kapas, vacum pump, tabung durham, kertas kopi, beaker glass,lampuspirtus, gelasukur, oven, dan ice box.

Media yang digunakan adalah Lactose Broth (LB), Brilliant Green Lactose Bile Broth (BGLBB), dan aquadest.

Pengambilan sampel air harus dilakukan secara aseptis dengan cara sebagai berikut: disiapkan botol sampel steril dengan volume \pm $100 \mathrm{ml}$ yang terbungkus kertas kopi.Botol diikat tali dan pasang pemberat di bagian dasar botol.Pembungkus dibuka, dan botol diturunkan perlahan-lahan ke dalam permukaan air, sampel diambil pada kedalaman $20 \mathrm{~cm}$ dibawah permukaan air.Setelah botol telah terisi penuh, tali ditarik sambil digulung, lalu sebagian isi botol dibuang hingga volume $\pm 3 / 4$ volume botol, bagian mulut botol dibakar, kemudian botol ditutup kembali (SNI 06-24121991).Diberi label yang mencantumkan kode/nomor sampel, asal lokasi sampel, dan waktu pengambilan sampel.Sampel dimasukkan ke ice box dan segera dibawa ke Laboratorium Bakteriologi Jurusan Analis Kesehatan.

Pemeriksaan sampel menggunakan metode Most Probable Number (MPN) ragam 3 $3 \quad 3$ penelitian ini dilakukan 2 tahap pemeriksaan, yaitu:

Uji Perkiraan (Presumtif test)

Disiapkan 3 tabung yang masing-masingberisi 5 $\mathrm{ml}$ media Lactose Broth (LB) triple strengthdan 6 tabung yang masing-masingberisi $10 \mathrm{ml}$ media Lactose Broth (LB) single strength yang disterilkan.Sampeldihomogenkandengancaradik ocok kemudian:Dipipet kedalam 3 tabung triple strength masing-masing sebanyak $10 \mathrm{ml}$ sampel.Dipipet $11 \mathrm{ml}$ sampeldandimasukkankedalam 3 tabungsingle $\begin{array}{lll}\text { strength.Dipipet } & 0,1 & \mathrm{ml}\end{array}$ sampeldandimasukkankedalam 3 tabungsingle strength.Dihomogenkan,

laludiinkubasipadasuhu $37^{\circ} \mathrm{C}$ selama 48 jam.

Interpretasihasil :

Positif (+): Terbentuk gas pada tabungdurham dan media keruh.

: Media bening atau media keruh tapi tidak terbentuk gas pada tabung durham. 
Uji Penegasan (Confirmated Test)

Jika uji penduga positif dipindahkan sampel pada 2 tabung yang berisi media BGLB masing-masing sebanyak 1 mata ose, lalu inkubasi pada suhu $37^{\circ} \mathrm{C}$ selama 48 jam.

Interpretasi hasil :

Positif (+):Terbentuk gas pada tabung durham dan media keruh.

Negatif (-):Media bening atau media keruh tapi tidak terbentuk gas pada tabung durham.

Hasil yang positifdikonfirmasidengantabel MPN $\quad \begin{array}{llll}3 & 3 & 3 & \text { menurut formula Thomas }\end{array}$ untukmemperoleh index MPN coliform per 100 $\mathrm{ml}$ sampel (Soemarno, 2000).

Data dianalisis univariat dan dilanjutkan dengananalisis bivariat untuk mengetahui ada tidaknya hubungan kualitas air dengan konstruksi sumur Uji statistik yang digunakan adalah deskriptif variabel katagorik.

\section{Hasil dan Pembahasan}

Hasil penelitian pemeriksaan total coliform pada 60 sampel air sumur gali di Dusun 3A Desa Karang Anyar Kecamatan Jati Agung Kabupaten Lampung Selatan, konstruksi sumur gali $100 \%$ tidak memenuhi syarat, dengan masing-masing komponen yang tidak memenuhi syarat yaitu $11,6 \%$ dinding sumur tidak memenuhi syarat, $15 \%$ bibir sumur tidak memenuhi syarat, 93,3\% lantai sumur tidak memenuhi syarat dan $100 \%$ saluran pembuangan air tidak memenuhi syarat. Komponen konstruksi yang tidak memenuhi syarat yaitu RT 01 meliputi $7,6 \%$ dinding sumur, $11,5 \%$ bibir sumur $88,4 \%$ lantai surflab $100 \%$ saluran pembuangan $14,7 \%$ dinding sumur $17,6 \%$ bibir sumur $97 \%$ lantai sumur $100 \%$ saluran pembuangan pada tabel berikut :

Tabel 1.Persentase konstruksi sumur gali di Dusun 3A Desa Karang Anyar Kecamatan Jati Agung Kabupaten Lampung Selatan

\begin{tabular}{ccc}
\hline Konstruksi Sumur Gali & Frekuensi & Persentase (\%) \\
\hline Memenuhi syarat & 0 & 0 \\
$\begin{array}{c}\text { Tidak memenuhi } \\
\text { syarat } \\
\text { Jumlah }\end{array}$ & 60 & 100 \\
\hline
\end{tabular}

Tabel 2.Persentase komponen konstruksi sumur gali di Dusun 3A Desa Karang Anyar Kecamatan Jati Agung Kabupaten Lampung Selatan

\begin{tabular}{ccc}
\hline Komponen & Frekuensi & Persentase (\%) \\
Konstruksi & & \\
Sumur Gali & & 11,6 \\
\hline Dinding sumur & 6 & 15 \\
Bibir sumur & 9 & 93,3 \\
Lantai sumur & 56 & 100 \\
$\quad$ Saluran & 60 & \\
pembuangan air & & \\
\hline
\end{tabular}

Tabel 3.Persentase komponen konstruksi sumur gali di RT 01 dan RT 02 di Dusun 3A Desa Karang Anyar Kecamatan Jati Agung Kabupaten Lampung Selatan

\begin{tabular}{|c|c|c|c|c|c|c|c|c|}
\hline \multirow{4}{*}{$\begin{array}{l}\text { Komponen } \\
\text { Konstruksi } \\
\text { Sumur Gali }\end{array}$} & \multicolumn{8}{|c|}{ Wilayah Dusun 3A } \\
\hline & \multicolumn{4}{|c|}{ RT 01} & \multicolumn{4}{|c|}{ RT 02} \\
\hline & \multicolumn{2}{|c|}{ MS } & \multicolumn{2}{|c|}{ TMS } & \multicolumn{2}{|c|}{ MS } & \multicolumn{2}{|c|}{ TMS } \\
\hline & $\mathrm{N}$ & $(\%)$ & $\mathrm{N}$ & $(\%)$ & $\mathrm{N}$ & $(\%)$ & $\mathrm{N}$ & $(\%)$ \\
\hline Dinding sumur & 24 & 92,4 & 2 & 7,6 & 29 & 85,3 & 5 & 14,7 \\
\hline Bibir sumur & 23 & 88,5 & 3 & 11,5 & 28 & 82,4 & 6 & 17,6 \\
\hline Lantai sumur & 3 & 11,6 & 23 & 88,4 & 1 & 3 & 33 & 97 \\
\hline $\begin{array}{c}\text { Saluran } \\
\text { pembuangan } \\
\text { air }\end{array}$ & 0 & 0 & 26 & 100 & 0 & 0 & 34 & 100 \\
\hline
\end{tabular}

Keterangan:

MS = Memenuhi Syarat

$\mathrm{N}=$ Jumlah

TMS $=$ Tidak Memenuhi Syarat

$(\%)=$ Persentase

Jarak sumber pencemaran dengan sumur gali di Dusun 3A Desa Karang Anyar dengan septic tank 4-14 meter ,dengan kandang ternak 3-10 meter, $100 \%$ tidak memenuhi syarat, dengan rincian $93,3 \%$ tidak memenuhi syarat jarak sumur dengan septic tank dan 100\%, dapat dilihat pada tabel 4, 5 dan 6.

Tabel 4.Persentasejarak sumur gali dengan sumber pencemaan di Dusun 3A Desa Karang Anyar Kecamatan Jati Agung Kabupaten Lampung Selatan

\begin{tabular}{ccc}
\hline $\begin{array}{c}\text { Jarak Sumber } \\
\text { Pencemaran }\end{array}$ & Frekuensi & $\begin{array}{c}\text { Persentase } \\
(\%)\end{array}$ \\
\hline Jarak Sumber & 0 & 0 \\
Pencemaran & & \\
memenuhi syarat \\
Jarak Sumber \\
$\begin{array}{c}\text { Pencemaran tidak } \\
\text { memenuhi syarat } \\
\text { Jumlah }\end{array}$ & 60 & 100 \\
\hline
\end{tabular}


Tabel 5.Persentase jarak sumur gali dengan sumber pencemaran yang tidak memenuhi syarat di Dusun 3A Desa Karang Anyar Kecamatan Jati Agung Kabupaten Lampung Selatan

\begin{tabular}{ccc}
\hline $\begin{array}{c}\text { Jarak dengan } \\
\text { sumber } \\
\text { pencemaran }\end{array}$ & Frekuensi & $\begin{array}{c}\text { Persentase } \\
(\%)\end{array}$ \\
\hline Septic tank & 56 & 93,3 \\
Kandang ternak & 60 & 100 \\
\hline
\end{tabular}

Tabel 6.Persentase jarak sumur gali dengan septic tank dan kandang ternak di RT 01 dan RT 02 di Dusun 3A Desa Karang Anyar Kecamatan Jati Agung Kabupaten Lampung Selatan

\begin{tabular}{|c|c|c|c|c|c|c|c|c|}
\hline \multirow{4}{*}{$\begin{array}{l}\text { Jarak dengan } \\
\text { sumber } \\
\text { pencemaran }\end{array}$} & \multicolumn{8}{|c|}{ Wilayah Dusun 3A } \\
\hline & \multicolumn{4}{|c|}{ RT 01} & \multicolumn{4}{|c|}{ RT 02} \\
\hline & \multicolumn{2}{|c|}{ MS } & \multicolumn{2}{|c|}{ TMS } & \multicolumn{2}{|c|}{ MS } & \multicolumn{2}{|c|}{ TMS } \\
\hline & $\mathrm{N}$ & $(\%)$ & $\mathrm{N}$ & $(\%)$ & $\mathrm{N}$ & $(\%)$ & $\mathrm{N}$ & $(\%)$ \\
\hline Septic tank & 4 & 92,4 & 22 & 7,6 & 0 & 0 & 34 & 100 \\
\hline $\begin{array}{c}\text { Kandang } \\
\text { ternak }\end{array}$ & 0 & 0 & 26 & 100 & 0 & 0 & 34 & 100 \\
\hline
\end{tabular}

Keterangan:

MS = Memenuhi Syarat

$\mathrm{N}=$ Jumlah

TMS $=$ Tidak Memenuhi Syarat

$(\%)=$ Persentase

Konstruksi sumur tidak memenuhi syarat $100 \%$. Total coliform $100 \%$ tidak memenuhi syarat, dari hasil tersebut maka ada hubungan antara konstruksi sumur terhadap total coliform dan ada hubungan antara jarak sumber pencemaran terhadap total coliform.

Hasil penelitian konstruksi sumur $100 \%$ tidak memenuhi syarat. Komponen konstruksi sumur gali lantai sumur $(93,3 \%)$ dan saluran pembuangan air (100\%). Jarak sumur gali dengan septic tank 4-14 meter dan jarak sumur gali dengan kandang ternak 3-10 meter 93,3\% tidak memenuhi syarat.Jarak sumur dengan kandang ternak $100 \%$ tidak memenuhi syarat.

Sejalan penelitian Novalino (2016) tentang kualitas air sumur gali di Kelurahan Lubuk Buaya Kecamatan Koto Tengah Kota Padang berdasarkan Indeks Most Probable Number (MPN) yaitu kondisi saluran pembuangan sumur gali yang diperiksa berpengaruh terhadap kualitas air sumur gali.

Hal ini disebabkan karena rendahnya pengetahuan masyarakat tentang kesehatan air dan sanitasi lingkungan menyebabkan masyarakat tidak menyadari adanya pencemaran air sumur gali karena konstruksi sumur dan jarak sumur dengan sumber pencemaran yang tidak memenuhi syarat. Masyarakat Desa Karang Anyar berpendidikan rendah tidak tamat $\mathrm{SD}$, berpendidikan tamat $\mathrm{SD}$ - SMP

Upaya pemerintah dalam menindak masalah sanitasi adalah program STBM (Sanitasi Total Berbasis Masyarakat). (Depkes RI, 2008).

Sejalan dengan penelitian Fitriani (2015) tentang gambaran kualitas bakteriologis air sumur gali di Kelurahan Sumber Agung Kecamatan Kemiling Kota Bandar Lampung, dari hasi uji regresi linier menunjukan hubungan sangat lemah antara jarak sumur dari septic tank terhadap jumlah MPN coliform dan hubungan yang sedang antara jarak sumur dari kandang ternak terhadap jumlah MPN coliform. Dan sejalan dengan penelitian Sapulete (2010) terdapat hubungan yang bermakna antara jarak sumur gali ke septic tank dan kandungan Escherichia coli dalam air sumur gali.

Simpulan dalam penelitian ini yaitu konstruksi sumur gali di Dusun 3A Desa Karang Anyar 100\% tidak memenuhi syarat, Jarak sumber pencemaran dengan sumur gali di Dusun 3A Desa Karang Anyar100\% tidak memenuhi syarat SNI-03-2916-1992. didapatkan hubungan antara kontruksi sumur terhadap total colifom air sumur gali, dan ada hubungan antara jarak sumber pencemaran terhadap total colifom air sumur gali.

\section{Daftar Pustaka}

1. ........ 2016, Profil Desa Karang Anyar, Kecamatan Jati Agung, Kabupaten Lampung Selatan.

2. Badan Standarisasi Nasional 1991, SNI 062412-1991 Tentang Metode Pengambilan Contoh Kualitas Air, Jakarta.

3. Badan Standarisasi Nasional 1992, SNI 032916-1992TentangSpesifikasi Sumur Gali untuk Sumber Air Bersih, Jakarta.

4. Departemen Kesehatan RI 2008, Strategi Nasional Sanitasi Total Berbasis Masyarakat. Depkes RI, Jakarta

5. Dewi, Kumala 2016, Gambaran MPN Coliform fekal Pada Air Sumur Gali di Desa Tanjung Sari VI Kecamatan Natar Kabupaten Lampung Selatan, KTI, Jurusan 
Analis Kesehatan Poltekkes Kemenkes Tanjungkarang.

6. Dinas Kesehatan Pemerintah Kabupaten Lampung Selatan 2015, Profil Kesehatan Kabupaten Lampung Selatan tahun 2014, Lampung Selatan.

7. Irianto, Koes 2013, Mikrobiologi Medis, Alfabeta, Bandung.

8. Marsono, 2009, Faktor-Faktor yang Berhubungan Dengan Kualitas Bakteriologis Air Sumur Gali di Pemukiman desa KarangAnom Kecamatan Klaten Utara, Tesis, Magister Kesehatan Lingkungan Universitas Diponegoro, Semarang.

9. Novalino, Amir, Suharti 2016, Kualitas Air Sumur Gali Kelurahan Lubuk Buaya Kecamatan Koto Tangah Kota Padang Berdasarkan Indeks Most Probable Number (MPN), Jurnal Kesehatan Andalas Volume 5, Nomor 3, FK Universitas Andalas.

10. Rahmadhani, Nurwahyu 2016, Gambaran MPN Coliform fekal Pada Air Sumur Gali di RW12 Kelurahan Hadimulyo Timur Kecamatan Metro Pusat Kota Metro, KTI, Jurusan Analis Kesehatan Poltekkes Kemenkes Tanjungkarang.

11. Soemarno 2000, Isolasi dan Identifikasi Bakteri Klinik, Akademi Analis Kesehatan, Yogyakarta.

12. Sopandi, Tatang, Wardah 2014, Mikrobiologi Pangan, ANDI, Yogyakarta.

13. Supardi, Imam, Sukamto 1999, Mikrobiologi Dalam Pengolahan Dan Keamanan Pangan, IKAPI, Bandung. 